Revista de Negócios_ISSN 1980.4431_vol. 18, n.2, p.44_61, 2013_DOI:10.7867/1980431.2013v18n2p44_61

\title{
As faces da aprendizagem de gerentes: $O$ caso de uma organização de microcrédito
}

\section{The faces of managers learning: The case of the microcredit organization}

Danilo Durigon

Uniplac Universidade do Planalto Catarinense - Brasil

ddurigon@santander.com.br

Fabiula Meneguete Vides da Silva

UFGD Universidade Federal da Grande Dourados - Brasil

fabiameneguete@yahoo.com.br

Elisabete Stradiotto Siqueira

UFERSA Universidade Federal Rural do Semi-Árido - Brasil

elisabete@ufersa.br

Erlaine Binotto

UFGD Universidade Federal da Grande Dourados - Brasil

binotto@ufgd.br

Cristiano José Castro de Almeida Cunha

UFSC Universidade Federal de Santa Catarina - Brasil

cunha@egc.ufsc.br

Recebido em 07 de junho de 2011. Alterado em 9 de agosto de 2012. Aprovado em 30 de novembro de 2012

Editor Responsável: Edson Roberto Scharf, Dr.

Processo de avaliação por double blind review

\section{Resumo}

O objetivo deste artigo é compreender como os executivos de uma organização de microcrédito aprendem a gerenciar diante dos desafios diários do trabalho. Para tanto foi realizada uma pesquisa de caráter qualitativo por meio de entrevista semiestruturada. As categorias de análise usadas para caracterizar os diversos componentes da aprendizagem foram: contexto; sentimentos relacionados; conteúdo; formas; os fatores que facilitam e dificultam o processo e os resultados do processo de aprendizagem e recomendações dos sujeitos. Os dados foram analisados através da análise de conteúdo. Os resultados demonstram que ao longo de suas vidas, tanto pessoal, quanto profissional, os sujeitos viveram situações que lhes exigiram entrar em um processo de aprendizagem e modificação de postura profissional e social. Convencionou-se chamar essas situações de contextos de aprendizagem. Identificaram-se nesta pesquisa dois tipos diferentes desses contextos: confronto com desafios, ambições e/ou pretensões futuras com relação ao seu crescimento profissional e diferentes estágios profissionais.

Palavras-chave: aprendizagem, gerentes, organização de microcrédito. 


\begin{abstract}
The aim of this text is to understand how executives from a microcredit organization learn how to manage facing the daily challenges of work. So, it was performed a qualitative research through semistructured interview. The categories of analysis used to characterize the various components of learning were: context, feelings related, content, forms, factors that facilitate and hinder the process and results of the learning process and recommendations of the subjects. Data were analyzed using content analysis. The results show that throughout their lives, both personal and professional, the subjects lived situations that required them to learn. Conventional to call these situations learning contexts. Were identified in this study these two different contexts: confronting challenges, ambitions and / or future claims related to your professional growth and different placements.
\end{abstract}

Keywords: learning, managers, microcredit organization.

\section{Introdução}

A realidade mutável que cerca as organizações provocou, ao longo dos últimos anos, mudanças significativas na gestão de pessoas. Essas mudanças relacionam-se, em parte, à nova postura adotada em relação ao perfil profissional desejado, ao investimento em treinamento e desenvolvimento, a gestão de carreira e a necessidade de aprendizado constante.

No que concerne ao quadro gerencial, essa necessidade é mais premente, considerando a complexidade presente em suas práticas e a responsabilidade em tratar a dimensão humana nas organizações.

Tais fatores se intensificam em um cenário em que as mudanças organizacionais tornaram-se mais presentes no contexto organizacional, demandando do gestor capacidade de lidar com tal processo. De acordo com Wood (1995, p. 46) a mudança organizacional é "o esforço para alterar as formas vigentes de cognição e ação, de maneira a capacitar a organização a implementar as estratégias por ela desenvolvidas".

No que concerne às instituições bancárias, as mudanças decorrentes de novas tecnologias e da competitividade no mercado com grandes corporações sendo criadas, promove grandes desafios ao quadro gerencial. Nesse contexto, encontra-se o Banco da Família que é uma Organização da Sociedade Civil de Interesse Público (OSCIP) denominada Associação Brasileira para o Desenvolvimento da Família (Banco da Família), criada no município de Lages (SC) em 1998 e que oferece microcrédito.

O Brasil foi um dos países pioneiros a experimentar o microcrédito para o setor informal urbano (1973), porém, somente em 2003, por meio da Resolução 3.106, o Banco Central do Brasil, através do conselho Monetário Nacional, aprovou o seu funcionamento no País. Desta forma, a maioria das entidades que concede microcrédito foi criada nos últimos dez anos e têm como característica comum o fato de serem constituídas sob a forma de pessoas jurídicas de direito privado sem fins lucrativos.

Segundo Landim (2006), visando segurança e rentabilidade, os bancos tradicionais privilegiam operações de maior volume e sistemas de garantias que não se ajustam às necessidades e às condições dos pequenos empreendimentos. Apresenta o Microcrédito como um dos instrumentos capazes de fornecer produtos e serviços financeiros adequados às necessidades específicas desses pequenos negócios, especialmente, crédito para o público de baixa renda.

Desta forma, os estudos relacionados a organizações de microcrédito são relevantes uma vez que constituem-se em alternativas para o desenvolvimento sócio econômico, como também constitui-se em uma forma de inclusão social.

Andrade, Binotto e Siqueira (2011) afirmam que o microcrédito possibilita o desenvolvimento econômico e social e que de acordo com o Banco Mundial países que disponibilizam para seus agentes econômicos, créditos superiores ao volume de suas unidades de bens e serviços produzidas têm economias mais evoluídas. No Brasil, a necessidade de democratizar o 
Danilo Durigon

Elisabete Stradiotto Siqueira

Cristiano José Castro de Almeida Cunha

crédito para parcelas da população de baixa renda, excluídas do sistema bancário tradicional vem merecendo destaque especial.

Nesse cenário de mudanças e de desafios, o Banco da Família procurou qualificar seus gestores buscando acompanhar as mudanças no mercado.

Contudo, se de um lado o Banco da Família atua no setor bancário, que tem uma racionalidade própria, por outro também interage com a lógica do microcrédito, que tem peculiaridades que em alguns momentos pode se constituir de forma contraditória, exigindo dos gestores desse tipo de organização a construção de lógicas administrativas próprias para a atuação em tais interfaces. A capacidade de aprendizagem é mais complexa uma vez que opera em uma lógica diferenciada da predominante no setor. Neste sentido, questiona-se como ocorre o processo de aprendizagem, em que medida este se produz de forma inovadora para atender as especificidades da organização, ou apenas adapta procedimentos presentes no setor bancário.

Para tratar tal problemática $\mathrm{o}$ objetivo deste artigo é compreender como os executivos de uma organização de microcrédito aprendem a gerenciar diante dos desafios diários do trabalho e das particularidades desse tipo de organização.

\section{Aprendizagem}

A temática aprendizagem tem sido bastante discutida no meio acadêmico e empresarial. Weick (1991) e Simon (1957) afirmam que a organização, por si só, não possui capacidade para aprender; na organização que aprende, o processo vai além do aspecto individual.

Nelson e Winter (1982) e Starbuck (1983) reforçam essa ideia ao considerarem que a evolução das organizações ocorre pela sua capacidade de aprender. As
Fabiula Meneguete Vides da Silva

Erlaine Binotto

organizações têm sistema cognitivo e memória (HEDBERG, 1981; WALSH; UNGSON, 1991); as rotinas e procedimentos trazem consigo histórias (NELSON; WINTER, 1982); o meio pelo qual o conhecimento é integrado depende da história e da cultura do grupo e da organização (BARNEY, 1986).

Antonello (2007, p. 5) ressalta que a aprendizagem é "[...] uma atividade social que acontece dentro de um ambiente participativo, onde a interação entre pessoas conduz a uma terceira dimensão instruída, o 'saber quem"”.

Neste sentido, se a aprendizagem é um ato social, as características intrínsecas de uma organização são fundamentais para definir como tal processo ocorre e como os indivíduos são influenciados por ele.

Carvalho (1999), em uma análise mais ampla, considera que o ato de aprender não quer dizer apenas estudar nos livros, "navegar" na Internet, passar horas diante do computador, ouvir exposições, palestras, ou literalmente decorar conhecimentos e informações. Todo este contexto faz parte da aprendizagem, mas, seu alcance é bem mais amplo. Aprender é um processo contínuo de adquirir novas posturas adequadas em relação às necessidades profissionais e vivenciais dentro de um determinado contexto.

Complementando a ideia da aprendizagem contínua, Freire (2005) entende que a aprendizagem não pode e nem deve ser levada em conta como um produto acabado, ou uma solução para resolver determinado problema, ou seja, não existe um modelo padrão para a aprendizagem. A aprendizagem é o resultado das práticas repetidas ou do aprender fazendo e do melhoramento contínuo (BANDURA, 1977).

Portanto, o contexto de atuação de uma organização também é fonte de aprendizagem, dado que as mudanças que ocorrem nesse cenário produzem novas demandas e desafios, reforçando o caráter 
contínuo do ato de aprender, por outro lado estar inserido em um setor mais amplo pode trazer conhecimentos que diferem da especificidade da organização em que o sujeito atua, desta forma, há necessidade de uma tradução ou adaptação daquilo que se aprende com o perfil cultural de cada organização.

Vasconcelos e Mascarenhas (2007) defendem que a aprendizagem pode ser compreendida como um processo de mudança de comportamento a partir do momento que há a aquisição de informações e conhecimentos que podem esclarecer as relações entre o sujeito e o meio social e produtivo em que está inserido. Esses autores concluem afirmando que a aprendizagem está relacionada, também, à identidade dos indivíduos, que a desenvolvem a partir da interação entre seus valores e comportamentos existenciais e os novos estímulos e experiências adquiridos no seu dia-a-dia. É justamente essa possibilidade de interação entre os conhecimentos mais amplos, aqueles das organizações e os pertinentes aos indivíduos que fazem da aprendizagem um processo singular.

\subsection{Aprendizagem Individual}

A aprendizagem no nível individual, segundo Marcon (2007), é um processo psicológico que ocorre na dimensão do sujeito e esse princípio vem sendo incorporado pela Administração, com o objetivo de explicar fenômenos de mudança no comportamento organizacional. Esse processo de mudança de comportamento do indivíduo não é resultante apenas da sua maturação, mas também da forma com que interage com o meio (ABBAD; BORGES-ANDRADE, 2004).

$\mathrm{Na}$ concepção de Swieringa e Wierdsma (1995) existem, pelo menos, dois processos básicos pelos quais a aprendizagem se efetiva nas organizações: aprendizagem natural e induzida. A aprendizagem natural ocorre a todo momento, informalmente, por tentativa e erro, imitação, busca de ajuda com outros profissionais, observação. A aprendizagem natural segue de acordo com o ritmo de desenvolvimento e o estilo pessoal de cada indivíduo. A aprendizagem natural é o modo mais primitivo de aprendizagem. $\mathrm{O}$ indivíduo tende a tomar outras pessoas como modelos, transformando-as, mesmo que inconscientemente, em educadores.

A aprendizagem induzida necessita de uma estruturação estabelecida para criar condições favoráveis para a aquisição, retenção e transferência de CHAs (Conhecimentos, Habilidades e Atitudes). Essas ações são conhecidas como treinamentos. No entanto, os treinamentos são apenas uma das formas de aprendizagem induzida que é composto pela abordagem de aprendizagem contínua, cada vez mais aderida pelas organizações para dar início ou continuidade às necessidades de mudança (SWIERINGA; WIERDSMA, 1995).

Em decorrência disso, os produtos da aprendizagem em contextos de trabalho são definidos em termos de desempenhos. Desempenho pode ser definido por um "Conjunto de comportamentos ligados a tarefas, papéis, normas, expectativas, metas e padrões de eficiência e eficácia estabelecidos em ambientes organizacionais" (ABBAD; BORGESANDRADE, 2004, p. 256). Ou ainda "Desempenho é o conjunto de entregas e resultados de determinada pessoa para a empresa ou o negócio" (DUTRA, 2004, p. 69).

Em outra perspectiva, Finger e Brand (2001) afirmam que o conceito de aprendizagem centra-se, principalmente, na dimensão cultural da organização. A cultura, de fato, não pode ser transformada sem que haja transformação ao mesmo tempo nas estruturas e na organização do trabalho. Desta forma, pode-se observar que o ambiente de trabalho é o principal responsável pela efetividade das ações de treinamento, desenvolvimento e educação sobre o desempenho individual e coletivo. Investigar, com prioridade no processo de aprendizagem gerencial, é condição para 
Danilo Durigon

Elisabete Stradiotto Siqueira

Cristiano José Castro de Almeida Cunha

promover o progresso da mudança organizacional, pois os gestores são os representantes legítimos dos valores, cultura e estratégia organizacional e, como consequência, são os principais agentes de mudança.

\subsection{Aprendizagem organizacional}

No que diz respeito ao contexto da aprendizagem organizacional, Antonello (2005) argumenta que esse conceito surgiu com maior força a partir dos anos 80. Suas premissas abrangem fatores como estratégia organizacional, cultura, estrutura organizacional e capacidade de resolução de problemas como determinantes dos resultados deste processo. Trata-se de "um processo de transformação pelo qual as partes interessadas da organização, individual e coletivamente, contribuem por meio de sua aprendizagem" (FINGER; BRAND, 2001, p. 172).

Antonello (2005) sustenta que tal conceito é complexo, pois se baseia na lógica de que uma organização, como uma entidade em si, é capaz de desenvolver um pensamento coletivo.

Swieringa e Wierdsma (1995) contribuíram significativamente nesse campo ao conceituarem aprendizagem organizacional como uma mudança do comportamento organizacional, um processo coletivo. Apresentam tal perspectiva como um potencial, uma competência, "aprender a aprender" e a mudança como uma demonstração do aprendizado. A condição para que uma organização aprenda é através da aprendizagem de seus membros, visto que quanto maior for o nível de autoconhecimento, maior será o potencial. Para os autores, aprendizagem é uma mudança de conduta; as pessoas devem criar e mudar a organização por meio da aprendizagem. A aprendizagem pode ocorrer de diversas formas:

- aprendizagem informal - aprender por imitação;
Fabiula Meneguete Vides da Silva

Erlaine Binotto

- aprendizagem formal - aprender com base em recompensas e castigos;

- aprendizagem mediante a experiência ou por meio da ação - o que se aprendeu deve ser evidenciado no que se faz;

- aprendizagem metódica - deve-se estar preocupado com uma maneira consciente de aprender;

- aprendizagem consciente - ajuda a desenvolver o potencial de aprendizagem e

- aprendizagem inconsciente - pela repetição.

A chave dos modelos de aprendizagem organizacional está no reconhecimento do modo como o processo é incorporado no contexto social, o que tem recebido especial atenção, considerando a maneira como as pessoas atribuem significado a suas experiências profissionais tácitas e explícitas (ANTAL et. al, 2001).

Dessa forma, Souza (2004, p. 8) faz a seguinte afirmação: "Enquanto organizar sugere a ordem, aprender sugere desordem, sendo que é a composição entre ordem e desordem o que está na raiz dos processos de mudança e aprendizagem organizacional".

Antal et. al. (2001) complementam essa idéia e afirmam que o aprender e o desaprender são processos permanentes; o desaprender é necessário porque o aprendizado não é simplesmente um processo cumulativo.

Para Hedberg (1981), o desaprender diz respeito ao questionamento e a reconstrução das perspectivas existentes, das estruturas conceituais de interpretação ou das premissas decisórias.

Tais perspectivas enfatizam 0 caráter inovador e produtor de mudanças possíveis quando uma organização se dedica a construir espaços de aprendizagem, e ao mesmo tempo evidenciam que uma organização que aprende diferencia-se das demais.

Ainda tratando da temática da 
aprendizagem no contexto organizacional é importante apresentar a distinção entre organização de aprendizagem (learning organizational) e aprendizagem organizacional (organizational learning). A organização de aprendizagem tem dado mais ênfase à observação e à análise distanciada dos processos que envolvem a aprendizagem individual e coletiva, buscando entender a natureza e o processo da aprendizagem (e desaprender) dentro das organizações. A aprendizagem organizacional orienta-se para a ação e está ajustada para usar ferramentas metodológicas específicas para realizar diagnósticos e avaliações, com o objetivo de identificar, promover e avaliar a qualidade dos processos de aprendizagem dentro da organização. Uma organização de aprendizagem é aquela que consegue obter aprendizagem organizacional (TSANG, 1997).

As expressões organizações de aprendizagem e aprendizagem organizacional eram utilizadas de forma confusa, porém o termo aprendizagem organizacional é, agora, adotado como uma expressão para as duas abordagens. Quando se trata da temática aprendizagem, é importante salientar que existem as dimensões organizacional, coletiva e individual. Nesse estudo o foco será a dimensão organizacional e a individual ou gerencial (EASTERBY-SMITH, 1997).

\subsubsection{Dimensões da capacidade de aprendizagem organizacional}

Finger e Brand (2001) sugerem seis dimensões da capacidade de aprendizagem de uma organização: individuais, coletivas, estruturais, culturais, resultantes da organização do trabalho, liderança de aprender e de promover a aprendizagem. Os mesmos autores oferecem alguns padrões para comparar os processos que podem conduzir a aprendizagem. Esses podem ainda servir de referência para medir o progresso ao longo das seis capacidades de aprendizagem.

Conforme já destacado, a capacidade individual de aprender pode ser identificada por meio da habilidade de um indivíduo de pensar de forma sistêmica e integrada, da habilidade de analisar criticamente e de interpretar informações com base no modelo mental de outra pessoa. Podem ser elaborados indicadores individuais para cada uma das habilidades, ou um único indicador que meça a capacidade global de aprender de um indivíduo (MARCON, 2007).

A capacidade coletiva de aprender tem como ponto de partida a existência de um grupo de indivíduos. Finger e Brand (2001) destacam que para mensurar essa capacidade, deve-se observar a capacidade de trabalho em equipe, a multifuncionalidade e a capacidade de lidar com o conflito de forma construtiva. Cada uma dessas capacidades pode ser medida em separado ou de forma global.

Segundo Marcon (2007), a capacidade estrutural de aprender preocupa-se com as características da estrutura organizacional que facilitam ou dificultam a aprendizagem individual e coletiva. A facilitação da aprendizagem está normalmente associada a estruturas descentralizadas, hierarquias horizontalizadas e unidades pequenas para permitir maior interação. Devido à sua complexidade, para medir essa capacidade, é sugerida a técnica da observação participante.

A capacidade cultural de aprender está associada à influência das normas e valores organizacionais na aprendizagem individual e coletiva. Culturas facilitadoras da aprendizagem demonstram características de transparência na comunicação, de tomada de risco incentivada, de diálogo, de confiança (MARCON, 2007).

Como técnicas para mensurar a capacidade cultural de aprender, Finger e Brand (2001) citam os questionários de diagnóstico de cultura, a análise de dados secundários, tais como, reclamações, críticas e sugestões e a observação participante.

Para Marcon (2007), a capacidade 
Danilo Durigon

Elisabete Stradiotto Siqueira

Cristiano José Castro de Almeida Cunha

de aprender da organização, em função da organização do trabalho, implica na definição dos processos internos de tal forma que a aprendizagem individual e coletiva seja favorecida. São exemplos de processos que facilitam a aprendizagem da organização: grupos de projetos, rotação de posições, sistemas de informações e equipes multifuncionais.

A capacidade da liderança de aprender e promover a aprendizagem revela a importante influência dos líderes no processo de aprendizagem individual e coletiva da organização, Argyris (2006) afirma que para a organização entrar num ciclo de raciocínio produtivo, e não defensivo, é importante começar a conscientização pela alta gerência. Os gestores seniores precisam perceber seus próprios raciocínios defensivos e consequências contraproducentes provocadas por eles. Como exemplos vivos dos valores e comportamentos legitimados pela organização, a maneira como os líderes preparam suas equipes, compartilham conhecimentos e informações e aceitam críticas e questionamentos, pode impactar em todo o ciclo de aprendizagem organizacional. Essa capacidade pode ser mensurada por meio da avaliação 360 graus, questionários aplicados nas equipes dos líderes e observação participante. O ritmo de desenvolvimento da equipe pode depender muito da capacidade do líder de aprender e promover a aprendizagem.

A chefia tem frequentemente um papel importante a desempenhar na explicação das implicações estratégicas de uma unidade de produção e na explicitação do motivo (do porquê) do que é exigido dos assalariados em relação à instauração de uma forma de reelaboração coletiva desse motivo (ZARIFIAN, 2001).

Em contrapartida, Nonaka e Takeuchi (1997) propõem o modelo gerencial middle-up-down (do-meio-paracima-e-para-baixo). Esse modelo ressalta a
Fabiula Meneguete Vides da Silva

Erlaine Binotto

importância do gerente intermediário, o qual desempenha um papel essencial no processo de criação do conhecimento, pois ele faz o elo entre os objetivos estratégicos da alta administração e a execução do planejamento estratégico no nível operacional. São os gerentes de nível médio que resumem o conhecimento explícito incorporando-os às práticas de gestão da organização. Para desempenhar esse papel de agentes do conhecimento, os gerentes intermediários necessitam de diversos requisitos, tais como, a capacidade de gestão de projetos, elaborar hipótese para criar novos conceitos e integrar metodologias para a criação do conhecimento. Além disso, é necessário que possua habilidade de comunicação na utilização de metáforas para ajudar os outros membros da equipe, despertar confiança e prever o curso de ação futuro, com base em uma compreensão do passado.

Os processos individuais de aprendizagem são fundamentais, embora não únicos, para $o$ processo de aprendizagem organizacional. Moraes, Silva e Cunha (2006) argumentam que para aprimorar a gestão nas empresas, é necessário estudar os processos de aprendizagem para a prática da gestão. $\mathrm{O}$ gestor é peça-chave na organização, pois suas entregas têm reflexo direto no desempenho de sua equipe e da organização.

Gomes (2004, p.201) sugere que em vez de estabelecer processos para sustentar os profissionais de competências e capacidades necessárias para o trabalho, sejam criados processos que estimulem as pessoas na geração, atualização e compartilhamento de competências. "A missão do gestor passou a ser favorecer os 'ciclos de aprendizagem', manter o desejo de auto-renovação, criar situações de trabalho estimulantes". 


\subsection{Aprendizagem Gerencial}

A teoria e a prática da aprendizagem gerencial têm recebido $o$ suporte de diferentes áreas do conhecimento, tais como: a Pedagogia e a Psicologia Organizacional e do Trabalho, as quais se destacam por serem áreas preocupadas com a educação e aprendizagem de adultos.

O principal conceito dessa abordagem é o de autodireção que define um grande desafio nos tempos atuais em que a gama de escolhas que se apresentam tornam-se cada vez maiores. Exercitar a assertividade e caminhar rumo à excelência no processo decisório torna-se essencial para o alcance de melhores resultados (KANAANE; ORTIGOSO, 2001, p. 160).

Para Kanaane e Ortigoso (2001), a autodireção e o autodesenvolvimento implicam na obrigação do indivíduo, enquanto gestor, de desenvolver continuamente seu potencial. $\mathrm{O}$ seu relacionamento formal e informal, a troca de experiência e vivências, o compartilhamento de objetivos e metas, a permanente interação com outras pessoas, quer sejam elas estabelecidas pela hierarquia quer não, podem influenciar positivamente para o alcance dos objetivos e metas da organização. Com isso, os gestores tendem a autodirecionar seu processo de aprendizagem gerencial através de recursos informais, como a leitura de livros, jornais, revistas, etc., ao invés de utilizarem somente recursos formais, como cursos de especialização.

\section{Caminhos metodológicos}

Conforme Yin (1994), trata-se de uma pesquisa de abordagem qualitativa que utilizou a estratégia do estudo de caso. O local do estudo foi o Banco da Família da cidade de Lages - SC, tendo sido entrevistados seis profissionais. A seleção dos entrevistados foi feita pelo método não probabilístico, e de forma intencional. Para tanto, alguns critérios foram estabelecidos para os respondentes: devem ter no mínimo dois anos de experiência em uma instituição de microcrédito e seis meses na função de coordenador ou gerente, não importando a sua formação profissional. Este período de dois anos de experiência e seis meses na função gerencial foi adotado como critério pelo fato de que é necessário algum tempo no cargo para que possa haver aprendizagem gerencial.

A coleta de dados foi realizada através de entrevistas semiestruturadas individuais que foram gravadas. Conforme sugerido por Merriam (1998), também, foram utilizadas, para registro dos dados coletados da entrevista, notas das observações e reflexões sobre o que estava se passando. $\mathrm{O}$ registro de notas foi utilizado para selecionar os aspectos mais importantes em relação ao sentido das respostas de cada sujeito e, também, com o intuito de descrever as expressões dos sujeitos e os seus comportamentos durante a entrevista.

$\mathrm{O}$ roteiro da entrevista buscou identificar os seguintes aspectos: contexto da aprendizagem; os sentimentos relacionados à aprendizagem; o conteúdo da aprendizagem; as formas de aprendizagem; os fatores que facilitam e dificultam o processo de aprendizagem; os resultados da aprendizagem e recomendações dos sujeitos.

Os dados foram analisados através da análise de conteúdo que, conforme Franco (2003) vem sendo empregada para gerar inferências sobre dados verbais e/ou simbólicos obtidos por meio de questionamentos e observações.

Para garantir o anonimato dos entrevistados, os mesmos serão classificados ao longo do texto como sujeito 1 , sujeito 2 , sujeito 3 , sujeito 4 , sujeito 5 e sujeito 6. Para efeito de destaque os textos relacionados aos relatos da entrevista serão apresentados em itálico.

\section{Análise dos dados}

Os dados serão apresentados seguindo as categorias de análise 
Danilo Durigon

Elisabete Stradiotto Siqueira

Cristiano José Castro de Almeida Cunha

previamente estabelecidas: contexto da aprendizagem, sentimentos relacionados à aprendizagem, conteúdo de aprendizagem, formas de aprendizagem, fatores que facilitam o processo de aprendizagem, fatores que dificultam o processo de aprendizagem, resultados da aprendizagem e recomendações dos sujeitos.

\section{1 $O$ contexto da aprendizagem gerencial}

No que diz a respeito ao contexto da aprendizagem gerencial, o sujeito $1 \mathrm{o}$ relaciona com desafios pessoais, nas diferentes empresas públicas e privadas que participou. Já o sujeito 3 relaciona o contexto a uma demanda, neste relato ele caracterizou uma situação onde um agente de crédito passou a assumir um cargo gerencial. Nesse caso, o conteúdo do trabalho muda gerando a necessidade de o profissional saber o que é a gestão. As situações que marcam a inconstância e as pressões inerentes ao trabalho gerencial exigem que o sujeito aprenda para ter capacidade de negociação e enfrente a mudança.

O sujeito 4 acredita serem os desafios - situações novas - que levam a aprendizagem. $\mathrm{O}$ sujeito 5 estabelece nexos com sua história pessoal com pais e professores que eram líderes e que lhe serviram de exemplo. Em relação ao confronto com desafios, ambições e/ou pretensões futuras com relação ao seu crescimento profissional, duas dimensões foram verificadas: mudanças na atividade desenvolvida e desafios do cargo que determinaram mudanças de comportamento para enfrentar os desafios que o cargo requer.

Estes fatores determinantes da aprendizagem estão de acordo com o proposto por Mezirow (1991) sobre uma atitude emancipatória do sujeito que define a aprendizagem transformativa do adulto, ou seja, que gera mudanças de consciência
Fabiula Meneguete Vides da Silva

Erlaine Binotto

crítica no indivíduo de acordo com novas situações profissionais e/ou outras que surgem na vida do indivíduo considerado.

Segundo os sujeitos, em determinados estágios eles sentiram demandas profissionais como relata o sujeito 6 que acredita não existir padrão. $\mathrm{O}$ sujeito 2 ressalta que [...] há que se destacar qual o estágio da carreira em que ele se encontra (inicial, intermediário, final).

A questão das demandas institucionais, também, pode variar de acordo com o tipo de empresa, conforme o relato do sujeito 1: [...] varia de empresa para empresa e é sentido ou experimentado de diferentes formas por cada indivíduo que nelas atuam, e que [...] há empresas que provocam e incentivam os seus colaboradores a assumirem posições de liderança, enquanto outras perseguem o objetivo de que o trabalho seja realizado, sem qualquer preocupação com a formação gerencial interna. Há, também as empresas ditas "familiares" onde o contexto de aprendizagem gerencial é quase inexistente; de outro lado, as empresas do setor público, com características peculiares que ora incentivam, ora não a aprendizagem gerencial.

Os relatos dos sujeitos sobre suas experiências no cargo gerencial vêm ao encontro da afirmação de Freire (1980) que acredita que a aprendizagem envolve uma tomada de consciência através de conteúdos, programas e métodos, fazendo com que o homem seja sujeito, estabelecendo com os outros relações de reciprocidade e de transformação do meio em que vive, fazendo com que o sujeito, ao longo de sua carreira profissional, passe por diversos estágios que requerem aprendizagem.

\subsection{Os sentimentos relacionados à aprendizagem gerencial}

Quando questionados sobre seus 
sentimentos em situações que lhes exigiam aprender, os sujeitos pesquisados relataram dois tipos: negativos e positivos. Contudo, o sujeito 3 acredita que aquilo que inicialmente era negativo pode se transformar. [...] Com certeza existem sentimentos negativos e positivos no processo de aprendizagem gerencial. Embora aqueles primeiramente considerados negativos possam transformarem-se em positivos (SUJEITO 3).

Os sentimentos negativos e positivos relatados pelo sujeito 1 são formas de superar limites. Ele acredita que a satisfação do trabalho que lhe é confiado produz seu aprendizado, conforme relatado a seguir: [...] a aprendizagem gerencial é marcada pelo desafio de superar os próprios limites e, com isso, fazer a diferença, seja no nível pessoal seja no social. Dê um lado temos a satisfação de que se é capaz de realizar o trabalho e, de outro, de que o trabalho é bem feito, bem executado, resultado na satisfação completa em fazer o trabalho que lhe é confiado (SUJEITO 1). Já o sujeito 2 diz por experiência própria que ansiedade em buscar o resultado deve existir e pode ser bem saudável em um processo. E o sujeito 5, disse que quase sempre está com sentimentos positivos, que é uma busca constante para ele, como relatou [...] estou sempre com sentimentos positivos, são de busca constante, pois exige segurança, determinação, entusiasmo. Com o sentimento ansiedade, trabalho com atividades adicionais ao trabalho, como a pratica de aulas de pilates (SUJEITO 5).

O sujeito 4 e 6 tem posições semelhantes ao relatarem que a insegurança é um dos principais aspectos negativos, contudo o sujeito 4 ressalta que a insegurança e a insatisfação pessoal são fatores de mudança.

\subsection{O conteúdo da aprendizagem gerencial}

Verificou-se que ser um gestor exige o conhecimento de tudo um pouco.
Kanaane e Ortigoso afirmam (2001, p.165) que "o modelo integrado de aprendizagem contempla o aprendizado individual, organizacional e a memória organizacional".

Os sujeitos 1 e 3 relatam que a aprendizagem é um processo contínuo, alinhando-se ao pensamento de Abbad e Borges-Andrade (2004, p. 256) sobre os produtos da aprendizagem em contextos de trabalho que são definidos em termos de desempenhos. E citam que o desempenho pode ser definido por um "Conjunto de comportamentos ligados a tarefas, papéis, normas, expectativas, metas e padrões de eficiência e eficácia estabelecidos em ambientes organizacionais".

O sujeito 6 afirma que [...] todo o conhecimento que adquiri nas funções já exercidas dentro desta instituição de microcrédito, vão muito alem do crescimento profissional, pois a área de atuação nos leva a uma reflexão acerca de tudo, pelos métodos utilizados. E poder retransmitir este conhecimento ao grupo, na função de líder é muito valoroso. As técnicas de gestão, trabalhadas sobre forma de procedimentos, nos faz também aprender muito.

O relato do sujeito 6 confirma a argumentação de Scharf (2007) de que a gestão do conhecimento é um conjunto de métodos para a criação, disseminação e uso do conhecimento dentro da organização, com o objetivo de aumentar as vantagens competitivas sustentáveis através da criação de valor compartilhada com o mercado.

O sujeito 4 relata que [...] considero como maior conteúdo o conhecimento adquirido, em todos os sentidos. Em relação ao relacionamento interpessoal, pois no contato diário vivenciamos muitas situações que nos ensinam a trabalhar com o outro e entendê-los, que vem de encontro a outro conteúdo, o autoconhecimento, pois conforme cada situação vivenciada, vamos aprendendo um pouco de nós mesmos e nossas reações em cada uma delas. Quando pensamos que estamos preparados para um determinado 
Danilo Durigon

Elisabete Stradiotto Siqueira

Cristiano José Castro de Almeida Cunha

problema e ele surge e tomamos uma decisão que pode não ser a mais correta, também aprendemos um pouco mais $e$ estamos conhecendo e aprimorando nosso potencial.

O sujeito 4 relata que valoriza o aprendizado das relações interpessoais, corroborando as proposições de Scharf (2007, p. 93) que destaca que a aprendizagem "[...] passa pelo estudo, discussão e compreensão das características e demandas do ambiente competitivo e entende o conhecimento como o ativo mais importante das empresas".

Os sujeitos 2 e 5 também valorizam o aprendizado das relações interpessoais, principalmente ao trabalhar com um público com demandas sociais significativas, consideram que essa especificidade do público alvo traz maiores responsabilidades no processo decisório.

\subsection{As formas de aprendizagem dos sujeitos}

Neste item sobre as formas de aprendizagem o sujeito 2 relata que [...] também aposta na ação, ou seja, aprendizado, através da prática direta e de ter em algum momento já vivenciado a situação para poder repassar e coordenar determinado trabalho. A experiência de vida como fonte de aprendizagem também é abordada pelo sujeito 6 .

Já o sujeito 3 relata que [...] também acredita que a atualização profissional, reciclagem de conhecimentos $e$ estar aberto a mudanças, também contribuem. As afirmações deste entrevistado estão de acordo com a argumentação de Freire (2005), quando diz que a aprendizagem não pode e nem deve ser levada em conta como um produto acabado, ou uma solução para resolver determinado problema, ou seja, não existe um modelo padrão para a aprendizagem.

$$
\text { O sujeito } 4 \text { relata que [...] }
$$

Fabiula Meneguete Vides da Silva

Erlaine Binotto

aprendemos muito no dia a dia. Este conhecimento adquirido no dia a dia relatado pelo sujeito 4, também, é citado por Carvalho (1999) que considera que a verdadeira aprendizagem só ocorre quando o indivíduo aprendiz dominou completamente o assunto objeto do aprendizado, domínio esse traduzido na aquisição de novas atitudes e habilidades.

O relato do sujeito 4, cita $o$ espelhar-se no líder conforme as proposições de Kim (1993) que usa a teoria da aprendizagem experimental para afirmar que aprendizagem do "saber como" é sobre habilidades e trabalho relacionados ao conhecimento e "saber por quê" é o conhecimento das convicções e valores. A interação consiste no fato de que o comportamento de cada indivíduo se torna estímulo para outro, desta maneira, ambas as formas de aprender permite a ligação entre pensamento e ação.

Através de recursos formais e informais de aprendizagem, o sujeito 1 relata que a atualização é importante. Esta autodireção da aprendizagem na fase adulta como relata o sujeito 1 é aquela proposta por Kanaane e Ortigoso (2001) que diz que a autodireção e o autodesenvolvimento acontecem quando o indivíduo tem a obrigação, enquanto gestor, de desenvolver continuamente seu potencial.

O sujeito 5 relata que como formas de aprendizado desenvolve [...] leituras, bom relacionamento. De acordo com este entrevistado, seu relacionamento formal e informal, a troca de experiência e vivências, o compartilhamento de objetivos e metas, a permanente interação com as outras pessoas, quer sejam elas estabelecidas pela hierarquia quer não, podem influenciar positivamente para o alcance dos objetivos e metas da organização, o sujeito 1 também se alinha à essa compreensão.

$\mathrm{O}$ relato do sujeito 1 e 5 reflete-se 
na citação de Kanaane e Ortigoso (2001, p. 161) que diz:

Gerenciar o conhecimento, as novas aprendizagens, colocando o conhecimento em ação, ativando-o e observando cuidadosamente as armadilhas que se apresentam no processo, contribuirão para maiores avanços quanto ao processo decisório e a autodireção auxiliando também a transacionar melhor com o erro e a tornar-nos, mais confiantes, menos estressados e ansiosos e mais abertos para novas experiências no processo de ensino/aprendizagem.

Após os relatos dos sujeitos, os mesmos destacaram sobre a atualização de leituras e participação em seminários.

\subsection{Os fatores que facilitaram a aprendizagem gerencial}

Entre os fatores que facilitam a aprendizagem relacionados à organização, o sujeito 3 relatou que [...] a própria oportunidade por parte da empresa, credibilidade ao trabalho já exercido.

$\mathrm{O}$ sujeito 1 relata que [...] as organização propiciaram as condições financeiras e materiais necessárias ao processo de aprendizagem, tais como: incentivo a participação em cursos, treinamentos, seminários, aquisição de material didático, etc. Esse posicionamento é compartilhado pelos sujeitos 1 e 6 .

As falas dos entrevistados 1,3 e 6 vão ao encontro da citação de Marcon (2007):

A capacidade cultural de aprender está associada à influência das normas e valores organizacionais na aprendizagem individual e coletiva. Culturas facilitadoras da aprendizagem demonstram características de transparência na comunicação, de tomada de risco incentivada, de diálogo, de confiança (MARCON, 2007, p. 48).

Como técnicas para mensurar a capacidade cultural de aprender, Finger e Brand (2001) citam os questionários de diagnóstico de cultura, a análise de dados secundários, tais como, reclamações, críticas e sugestões e a observação participante.
Em relação aos fatores motivacionais relativos aos próprios sujeitos entrevistados, o sujeito 6 afirma que são [...] a vontade e o prazer de aprender cada vez mais, de saber cada vez mais.

Já o sujeito 3 relata que é [...] $a$ vontade de manter-se envolvida e gostar $e$ acreditar no trabalho em equipe.

O sujeito 5 cita como motivo o [...] crescimento da organização, a força de vontade de aprender $e$ desenvolver um bom trabalho. Gosto de trabalhar em equipe, e frisou dizendo que [...] me identifico com a missão do Banco.

O sujeito 4 ressalta: [...] acredito que os principais responsáveis pelo nosso desenvolvimento profissional somos nós mesmos, mas, oportunidade, credibilidade e autonomia oferecidos pela empresa facilitaram muito o aprendizado, sem estes seria difícil aprender, se você não tem oportunidade de vivenciar uma liderança, fica mais difícil aprender, da mesma forma se você tem a oportunidade de gerenciar, mas, não tem credibilidade e autonomia, também, tem dificuldade em aprender.

$\mathrm{O}$ relato do sujeito 4 alinha-se à argumentação do autor Marcon (2007) que acredita que a capacidade de aprender da organização, em função da organização do trabalho, implica na definição dos processos internos de tal forma que a aprendizagem individual e coletiva seja favorecida. São exemplos de processos que facilitam a aprendizagem da organização: grupos de projetos, rotação de posições, sistemas de informações e equipes multifuncionais.

\subsection{Os fatores que dificultaram a aprendizagem gerencial}

No que se refere às dificuldades vividas o sujeito 1 relata que [...] as dificuldades intrínsecas: tempo, principalmente decorrente do acúmulo de funções profissionais $e$ as atribuições da vida familiar (esposa, filhos, etc.), tal posicionamento é compartilhado pelo sujeito 3 .

O sujeito 5 relatou que [...] gosto de 
Danilo Durigon

Elisabete Stradiotto Siqueira

Cristiano José Castro de Almeida Cunha

residir em Lages, então não aceitei a proposta de mudar de cidade, demais fatores como dinheiro, interesse pessoal, ok. Estou sempre em busca, sou motivada.

Os fatores extrínsecos que dificultaram a aprendizagem foram assinalados pelo sujeito 2 como[...] não disponibilidade no local de residência dos cursos de aperfeiçoamentos necessários, na hora necessária.

$\mathrm{O}$ sujeito 6 relata que [...] de uma forma geral, acredito que o que pode ser considerado um pouco negativo seria o acúmulo de muitas atividades, embora isso, também nos venha trazer experiência, até mesmo no sentido de saber priorizar e delegar tarefas.

O sujeito 4 relatou que [...] $o$ acúmulo de atividades foi um fator que dificultou bastante o aprendizado, pois, com várias tarefas a serem executados $e$ com prazo a ser cumprido, ficou mais difícil o aprimoramento em determinados áreas. Você acaba dedicando muito tempo as atividades rotineiras, pois precisa cumprí-las e acaba deixando o aprendizado um pouco esquecido.

Os fatores que dificultaram a aprendizagem dos sujeitos foram classificados em duas propriedades: intrínsecos e extrínsecos ao sujeito.

\subsection{Os resultados da aprendizagem gerencial}

Os sujeitos definiram que os resultados da aprendizagem gerencial podem ser tanto profissionais, quanto pessoais. Do lado profissional o sujeito 1 relatou que [...] no tocante ao lado profissional temos a vantagem de poder obter beneficios e vantagens financeiras melhores nas empresas onde atuam.

Já o sujeito 3 relata que [...] a partir do momento em que você se envolve em um projeto da empresa, isto irá trazer ferramentas que poderão ser usadas, não somente em um processo, mas sim, em
Fabiula Meneguete Vides da Silva

Erlaine Binotto

outros a frente, a isso se chama experiência, você passa a ver de maneira diferente e ter meios para ação.

Em relação ao lado pessoal o sujeito 1 relatou que [...] em ser uma pessoa melhor, com habilidades de relacionamento e sociais mais desenvolvidas, encarando de forma mais tranqüila as facetas da vida.

Já o sujeito 2 relata que [...] esta aprendizagem nos permite uma bagagem para a vida, no sentido em que contribui com diversos temas que podem ser aplicados a nossa vida pratica. Quanto ao desenvolvimento profissional é um conhecimento que jamais se perde. Com isso, ajudou-os no crescimento dos sujeitos na instituição de microcrédito e nos resultados operacionais.

Sobre este aspecto, o sujeito 6 relatou: [...] tenho visão da instituição como um todo, como sendo meu próprio negócio, seguindo sempre com o cumprimento dos procedimentos operacionais. Acredito que consigo contribuir para a instituição com minha experiência para meu desenvolvimento pessoal e profissional.

O sujeito 4 fala sobre [...] melhora do clima organizacional, segurança na tomada de decisões, mudança de comportamentos e valores, visão mais ampla.

Já o sujeito 5 afirmou que [...] humildade e apoio da equipe e superiores são fundamentais para um bom trabalho.

Os relatos do sujeito 4 e 5 identificam-se com a literatura especializada, conforme destacado por Fleury e Fleury (1997, p. 20):

O processo de aprendizagem em uma organização não só envolve a elaboração de novos mapas cognitivos, que possibilitem compreender melhor o que está ocorrendo em seu ambiente externo e interno, como também, a definição de novos comportamentos, que comprovam a efetividade do aprendizado.

Ao aprenderam sobre si mesmos os 
sujeitos desenvolveram uma postura adequada ao trabalho, à capacidade de tomar decisões, a maturidade e a coragem o que vem ao encontro com as atuais discussões sobre o trabalho gerencial. Kotter $(1982,1999)$ destaca a divergência entre a sabedoria convencional e o comportamento gerencial observado em suas pesquisas. A concepção convencional sustenta-se nas atividades de planejamento, controle, organização e direção. Somam-se à abordagem clássica, por exemplo, as atividades de relacionamentos, tomada de decisões e transferência de informações, numa perspectiva de trabalho bastante fragmentada.

\subsection{As recomendações dos sujeitos sobre a aprendizagem gerencial}

Por fim, identificaram-se as recomendações dos sujeitos a respeito da aprendizagem gerencial. Os sujeitos 1 e 3 sugeriram que os gerentes e coordenadores devem ter um projeto pessoal de vida, tirar proveito de suas experiências, compreender os valores e metas da organização, valorizar relacionamentos e diversificar conhecimentos como relata o sujeito 5 [...] trabalhamos a palavra "liderança", pois lideramos pessoas e gerenciamos coisas.

É o que sugere o sujeito 4 quando relata que [...] apenas uma observação sobre feedback, que é um fator que pode facilitar a aprendizagem desde que colocado em prática, pois precisamos saber ouvir e aproveitar os feedbacks recebidos. Acredito que a falta de feedback pode dificultar o crescimento profissional.

Os sujeitos 2 e 6 consideram que a organização deve desenvolver tais valores na cultura organizacional da empresa, visto que em alguns momentos a hierarquia e centralização de decisões dificultam a aprendizagem gerencial.

\section{Considerações finais}

O objetivo dessa pesquisa foi compreender como os executivos de uma organização de microcrédito aprendem a gerenciar diante dos desafios diários do trabalho. Ao longo de suas vidas, tanto pessoal, quanto profissional, os sujeitos viveram situações que lhes exigiram aprender. Convencionou-se chamar essas situações de contextos de aprendizagem. Identificaram-se nesta pesquisa dois tipos diferentes desses contextos: confronto com desafios, ambições e ou pretensões futuras com relação ao seu crescimento profissional e diferentes estágios profissionais.

De acordo com os dados colhidos, as demandas profissionais de aprendizagem se originam quando os sujeitos sentem falta de conhecimentos, atitudes e/ou habilidades adequadas para o exercício da função gerencial naquele estágio de suas carreiras.

No caso das demandas institucionais, a necessidade de aprender tem origem na empresa que passa a exigir dos gerentes e coordenadores novos conhecimentos, habilidades ou atitudes para que possam, por exemplo, adotar um novo modelo de gestão bancária ou atender novas exigências do setor de microcrédito, compondo o conjunto de entregas e resultados de determinado sujeito para a empresa (DUTRA, 2004).

Mostrou-se, também, que os gerentes e coordenadores aprenderam de diferentes formas, as quais caracterizam a natureza complexa e dinâmica da aprendizagem gerencial. Essas formas de aprendizagem foram classificadas nas seguintes propriedades: técnicas de aprendizagem, atualização profissional, relacionamentos, observação, liderança, vivência, reflexão e mudança de consciência.

Foi relatado pelos sujeitos pesquisados que os resultados de sua aprendizagem são relativos ao autoconhecimento e ao conhecimento sobre a organização, bem como, ao desenvolvimento profissional, de uma forma geral.

Já a complexidade do processo de 
Danilo Durigon

Elisabete Stradiotto Siqueira

Cristiano José Castro de Almeida Cunha

aprendizagem gerencial foi detectada no fato que sua natureza é tanto social e emancipatória, quanto autodirecionada e dependendo do contexto e conteúdo de aprendizagem, diferentes mecanismos serão acessados.

Compreender a aprendizagem gerencial como um processo dinâmico e complexo é enxergá-la de forma ampla, buscando sua totalidade.

A concepção que temos das coisas não é plenamente natural, mas, um produto histórico de um contexto social particular. O domínio social refere-se à influência do ambiente cultural na formação, ao longo da vida, das estruturas de significados pelas quais os gestores irão interpretar suas experiências e guiar suas ações, seja em relação à cultura acadêmica apreendida, seja em relação aos valores morais adquiridos com a família (MEZIROW, 1991).

O domínio organizacional relaciona-se com o ambiente de trabalho em que os gestores estão envolvidos. É neste domínio que se formam os contextos de aprendizagem, bem como, os fatores que podem formar um clima propício à sua aprendizagem.

Por fim, o domínio individual evidencia a forma única com que cada gerente ou coordenador irá interpretar as experiências, com base nas suas perspectivas de vida, e determinar seu padrão de ação dentro da organização.

As descobertas descritas mostram que a natureza do processo de aprendizagem gerencial abrange tanto a autodireção, quanto aspectos sociais e emancipatórios da aprendizagem.

Conclui-se, a partir da pesquisa apresentada, que a aprendizagem gerencial:

- transcende a classificação formal e informal, pois em grande parte, ocorre acidentalmente;
Fabiula Meneguete Vides da Silva

Erlaine Binotto

- não se restringe ao domínio instrumental de conhecimento, isto é, à aquisição de habilidades analíticas;

- é influenciada pelo contexto organizacional, o qual é responsável pelo clima de aprendizagem na organização;

- é influenciada pelo contexto social, ou seja, pelo conjunto de pessoas com que o gestor interage em sua trajetória de vida e de participação na organização;

- pode ocorrer através de mudanças de consciência originadas com a reflexão crítica de estruturas de significado construídas socialmente e que restringem sua ação profissional.

Programas de educação e desenvolvimento gerencial deveriam questionar suas metodologias de ensinoaprendizagem, considerando, além de "o que" e "como" os gestores aprendem os temas abordados na pesquisa, envolvidos no processo de aprendizagem.

Organizações deveriam preocuparse com a construção de ambientes favoráveis para a aprendizagem gerencial e estimular a aprendizagem que ocorre no ambiente de trabalho, o que pode aumentar os resultados gerenciais positivos sem aumentar os custos com educação e desenvolvimento.

Gestores deveriam ampliar suas redes de relacionamento, tanto dentro, como fora da empresa de modo a potencializar sua aprendizagem, tendo em vista que a maior parte dela ocorre através de relacionamentos. E dessa forma, aprimorar sua performance com a troca de experiência com outros gestores de outras instituições.

Espera-se que a discussão conduzida auxilie os gestores em sua árdua tarefa de aprender, de modo a enfrentar os desafios diários de seus trabalhos. Mais do que isso, espera-se possibilitar aos gestores de organizações, especialmente as de micro crédito, a utilização de formas de aprendizagem que lhes permitam um 
exame crítico das pressuposições que estão por trás de comportamentos e de atitudes disfuncionais (rejeição, falta de empatia entre os membros da família, falta de limites claros, ordens e mensagens não muito claras, manipuladores, etc.), os quais restringem sua ação diante dos problemas de sua época.

Como limitações dessa pesquisa temos o número restrito de sujeitos. Como estudos futuros sugere-se uma análise comparativa no contexto do setor bancário, entre organizações de microcrédito e aquelas convencionais, a fim de compreender se os ambientes de trabalho diferenciados proporcionam perspectivas conceituais diferenciadas.

\section{Referências}

ABBAD, G.; BORGES-ANDRADE, J. Aprendizagem Humana em Organizações de Trabalho. In: ZANELLI, J.C. BORGES-ANDRADE, J. BASTOS, A.V. (Org). Psicologia, organização e trabalho no Brasil. Porto Alegre: Artmed, 2004.

ANDRADE, S. A.; BINOTTO, E.; SIQUEIRA, E. S. Microcrédito produtivo nos negócios informais urbanos: contribuições e limites. Pespectivas Contemporâneas, Campo Mourão, v. 6, n. 1, 2011.

ANTAL, A. B.; LENHARDT, U.; ROSENBROCK, R. Barriers to Organizational Learning. In: DIERKES, M.; et al. Handbook Organizational Learning and Knowledge. Oxford: Oxford University Press, p. 865 - 885, 2001.

ANTONELlO, C. S. A metamorfose da aprendizagem organizacional: uma revisão crítica. In: RUAS, R.; ANTONELlO, C.; BOFF, L. H. (Org). Aprendizagem organizacional e competências. Porto Alegre: Bookman, 2005.

ANTONELLO, Claudia S.. O processo de aprendizagem interníveis e o desenvolvimento de competências. São Paulo:
Revista Brasileira de Gestão e Negócios, v. 9, n. 25, 2007.

ARAÚJO, Luiz César. Organização, Sistemas e Métodos e as modernas ferramentas de gestão educacional. São Paulo: Atlas, 2004.

ARGYRIS, C. Ensinando pessoas inteligentes a aprender. In: Aprendizagem Organizacional: os melhores artigos da Harvard Business Review. Rio de Janeiro: Elsevier, 2006.

\section{BANDURA, A. Social learning theory.}

Englewood Cliffs, N.J: Prentice Hal, 1977.

BARBOSA, L. Igualdade e Meritocracia: a ética do desempenho nas sociedades modernas. Rio de Janeiro: FGV, 2001.

BARNEY, J. B. Organizational Culture: Can it be a source of sustained competitive advantage? Academy of Management Review. v. 11, n. 3, p. 656 - 665, 1986.

CARVALHO, Antônio Vieira de. Aprendizagem organizacional em tempos de mudança. São Paulo: Pioneira, 1999.

DUTRA, J. Competências: conceitos e instrumentos para a gestão de pessoas na empresa moderna. São Paulo: Atlas, 2004.

FINGER, M; BRAND, S. B. Conceito de "Organização de Aprendizagem" aplicado à transformação do Setor Público: contribuições conceituais ao desenvolvimento da teoria. In: EASTERBYSMITH, M., BURGOYNE, J.; ARAÚJO, L. Aprendizagem Organizacional e Organização de Aprendizagem. São Paulo: Atlas, p. 165- 192, 2001.

FLEURY, Afonso e FLEURY, Maria T. L. Aprendizagem e inovação organizacional: As experiências de Japão, Coréia e Brasil. 2. ed., São Paulo: Atlas, 1997.

FRANCO, T.B. e MAGALHÃES, JR. Atenção Secundária e a Organização 
Danilo Durigon

Elisabete Stradiotto Siqueira

Cristiano José Castro de Almeida Cunha

das Linhas de Cuidado. In: MERHY et al. O Trabalho em Saúde: olhando e experien-ciando o SUS no cotidiano. São Paulo, HUCITEC, 2003.

FREIRE, Paulo. Conscientização: teoria e prática da libertação - uma introdução ao pensamento de Paulo Freire. São Paulo: Moraes, 1980.

FREIRE, Paulo. Pedagogia do oprimido, 41 ${ }^{\mathrm{a}}$ ed., Rio de Janeiro: Paz e Terra, 2005.

GOMES, J. F. A terceira competência. Rio de Janeiro: Qualitymark, 2004.

HEDBERG, B. How Organizations Learn and Unlearn. In: NYSTROM, P.C.; STARBUCK, W.H (eds.). Handbook of Organizational Design. New York: Oxford University Press, p. 3 - 27, 1981.

KANAANE, R. O. Sandra Aparecida Formigari. Manual de treinamento e desenvolvimento do potencial humano. São Paulo: Atlas, 2001.

KIERNAN, M. J. Os 11 mandamentos da administração do século XXI. São Paulo: Makron Books, 1998.

KIM, D. H. The link between individual and organizational learning. Cambride: Sloan Management Review, v. 35, n. 1, 1993.

KOTTER, P. J. What effective general managers really do? Harvard Business Review, v. 60, n. 6, p. 156-167, 1982.

What effective general managers really do? Harvard Business Review. March/ april, p. 145-160, 1999.

LANDIM, C. C. M. O Microcrédito no Estado da Bahia: a experiência da Instituição de Crédito Itabuna. 2006.

MANACORDA, M. A. História da Educação: da antiguidade aos nossos dias. Tradução de Caetano Lo Monoco; revisão da tradução Rosa dos Anjos
Fabiula Meneguete Vides da Silva

Erlaine Binotto

Oliveira e Paolo Nosella. 6. ed. São Paulo: Cortez. 1997.

MARCON, C. E. Competências gerenciais e suas contribuições no processo de aprendizagem organizacional: um estudo empírico em empresa do setor de telecomunicações brasileiro. 2007. $107 \mathrm{f}$. Dissertação. (Pós-Graduação em Administração). Faculdade de Economia, Administração, Contabilidade e Ciência da Informação e Documentação (FACE). Universidade de Brasília, Brasília. 2007.

MERRIAM, S. Qualitative research and case study applications in education. San Francisco: Jossey-Bass, 1998.

MEZIROW, J. Transformative dimensions of adult learning. San Francisco (USA): Jossey-Bass, 1991.

MORAES, L. V., SILVA, M. A, CUNHA, C. A dinâmica da aprendizagem gerencial em um hospital. RAE-Eletrônica, v. 5, n. 1, Art. 3, jan./jun., 2006.

NELSON, R. R.; WINTER, S. G. An evolutionary theory of economic change. Cambridge: Belknap Press of Harvard University Press, 1982.

NONAKA, Ikujiro. TAKEUCHI, Hirotaka. Criação de conhecimento na empresa: como as empresas japonesas geram a dinâmica da inovação. Rio de Janeiro: Elsevier, 1997.

PEDRINI, A de G. (org.). Educação Ambiental: reflexões e práticas contempo-râneas. Petrópolis, Rio de Janeiro: Vozes, 1998.

ROESCH, S. M. A. Projetos de estágio e de pesquisa em Administração: guia para estágios,trabalho de conclusão, disserta-ções e estudos de caso. 2. ed. São Paulo: Atlas, 1999.

SCHARF, Edson R. Gestão do conhecimento aplicada ao Marketing. Florianópolis: Visual Books, 2007. 
SIMON, H. A. Administrative behavior: a study of decision making process in administrative organization. New York: Macmillan, 1957.

SOUZA, Y. S. Organizações de Aprendizagem ou Aprendizagem Organizacional. RAE-Eletrônica, v. 3, n. 1, jan./jun. 2004.

STARBUCK, W. H. Organizations as Action Generators. American Sociological Review. v. 48, n. 1, p. 91- 102, 1983.

SWIERINGA, J; WIERDSMA, A. La organización que aprende. Wilmington: Addidon-Wesley, 1995.

TSANG, E. W. K. Organizational Learning and the Learning Organization: a dichotomy between descriptive and prescriptive research. Human Relations, v. 50, n. 1, p. 73- 89, 1997.

VASCONCELOS, I. F. G., MASCARENHAS, A. O. Organização em aprendizagem. São Paulo: Thomson Learning, 2007.

ZARIFIAN, P. Objetivo Competência. São Paulo: Atlas, 2001.

YIN, Robert K. Case Study Research. Design and Methods. London: SAGE, 1994.

WALSH, J. P.; UNGSON, G. R. Organizational Memory. Academy of Management Review, v. 16, n. 1, p. 5791, 1991.

WEICK, K. E. The Nontraditional Quality of Organizational Learning. Organization Science. v. 2, n. 1, p. 116- 124, 1991. 